\title{
Comparative Analysis of Frequency and Structure of Complications after Various Options of Tracheostomy
}

\section{Otabek Eshonkhodjaev, Shuhrat Khudaybergenov, Ravshan Ibadov, Rustem Hayaliev, Anvar Yormuhammedov}

Republican Specialized Center of Surgery Named of Academician V. Vakhidov, Tashkent, Uzbekistan

Email:rustemmed@rambler.ru

How to cite this paper: Eshonkhodjaev, O., Khudaybergenov, S., Ibadov, R., Hayalive, R. and Yormuhammedov, A. (2020) Comparative Analysis of Frequency and Structure of Complications after Various Options of Tracheostomy. Open Journal of Thoracic Surgery, 10, 41-55.

https://doi.org/10.4236/ojts.2020.102005

Received: June 5, 2020

Accepted: June 26, 2020

Published: June 29, 2020

Copyright $\odot 2020$ by author(s) and Scientific Research Publishing Inc. This work is licensed under the Creative Commons Attribution International License (CC BY 4.0).

http://creativecommons.org/licenses/by/4.0/

\begin{abstract}
The article presents a new technique developed by RSCS named after acad. V. Vakhidov for performing percutaneous dilatational tracheostomy by using the improved Howard-Kelly forceps, which ensures stable traction of the guidewire and reduces the risk of trauma to surrounding tissues. In order to assess the feasibility and necessity of carrying out a modified method of tracheostomy, a comparative analysis of the frequency and structure of complications after various options for tracheostomy was carried out, taking into account the presence or absence of risk factors for an adverse outcome.
\end{abstract}

\section{Keywords}

Percutaneous Tracheostomy (PTS), Modified Percutaneous Tracheostomy (MPTS), Bronchoscopy, Tracheal Stenosis, Multiple Organ Failure (MOF)

\section{Introduction}

As shown, the analysis of the most significant world publications (Social Sciences Citation Index, SSCI $\geq 10$ ) in the National Library of Medicine database of the National Institutes of Health determined the high significance of the problem of tracheostomy and post-tracheostomy complications [1] [2].

S. G. Durbin (2010) states that at least ten percent of patients who need at least three days of artificial lung ventilation (ALV) need to perform tracheostomy in order to ensure the patency of the respiratory tract and PMV [3], as confirmed by the opinion of V. D. Parshin (2008), “...after 7 days of translaryngeal intubation, pronounced ( 3 - 4 degree) damage to the larynx and vocal folds is formed on the Lindhom C. E. scale (1969)". 
To date, there are numerous methods of percutaneous dilated tracheostomy (PDT), however, the advantages of any method are questionable, since each of them has its own technical difficulties, which requires further improvement [4] [5] [6].

In a recent issue of Critical Care, Simon M. where colleagues present a systematic review of risk factors vital complications of PDT, which coincides with the opinion of a large number of researchers "...this procedure is for high-risk" in connection with which the search continues for the proposals to improve the safety of tracheostomy patients on PALV [1] [2].

In this regard, in this Chapter, we have presented the improved methods of standard dilational tracheostomy developed at the RSCS named after acad. Vakhidov, the priority of these methods was not only to achieve maximum safety of the procedure, but also to avoid subsequent complications, such as bleeding and cicatrical stenosis of the trachea.

In this regard, we have developed the author's models (utility model \#1 and \#2) modification of the Howard-Kelly forceps for PDT.

\section{Advanced Versions of the Instrument for Performing Percutaneous Dilatational Tracheostomy}

The purpose of developing the modified forceps was to simplify and improve usability. To solve this goal, we have proposed a forceps for clamping and holding organs and tissues during tracheostomy, containing branchlets with kremallera and working sponges with longitudinal grooves along the width of the sponges and applying mesh knurling on the side surfaces of the working sponges, with grooves in the working sponges, and in the longitudinal groove of the second working sponge, a side hole is made for conducting a guidewire.

Comparative analysis with the prototype (Howard-Kelly forceps) showed that the claimed device differs from the known one in that the working sponges have grooves, and in the longitudinal groove of the second working sponge, a side hole is made for conducting the guidewire. These distinctive features allow us to draw a conclusion about the novelty of the technical solution. Performing grooves in the working sponges and placing the first working sponge of the conductor-string in the longitudinal groove makes it easier to insert and directs the guidewire in the desired direction during tracheostomy. Performing a side hole on the longitudinal groove of the second working sponge makes it easier to use when fixing the guidewire.

Thus, the proposed device has a novelty and can be applied in a wide surgical practice. Figure 1 shows the diagram of utility model \#1 for performing percutaneous dilatational tracheostomy. Figure 2 shows the actual type of clips for performing percutaneous dilated tracheostomy with and without guidewire.

Description of the clamp for holding organs and tissues during tracheostomy (Figure 1): the Clamp contains branches 1 and 2 with a cremallera 3 and working sponges 4 and 5 with longitudinal grooves 6 and 7 across the width of the 


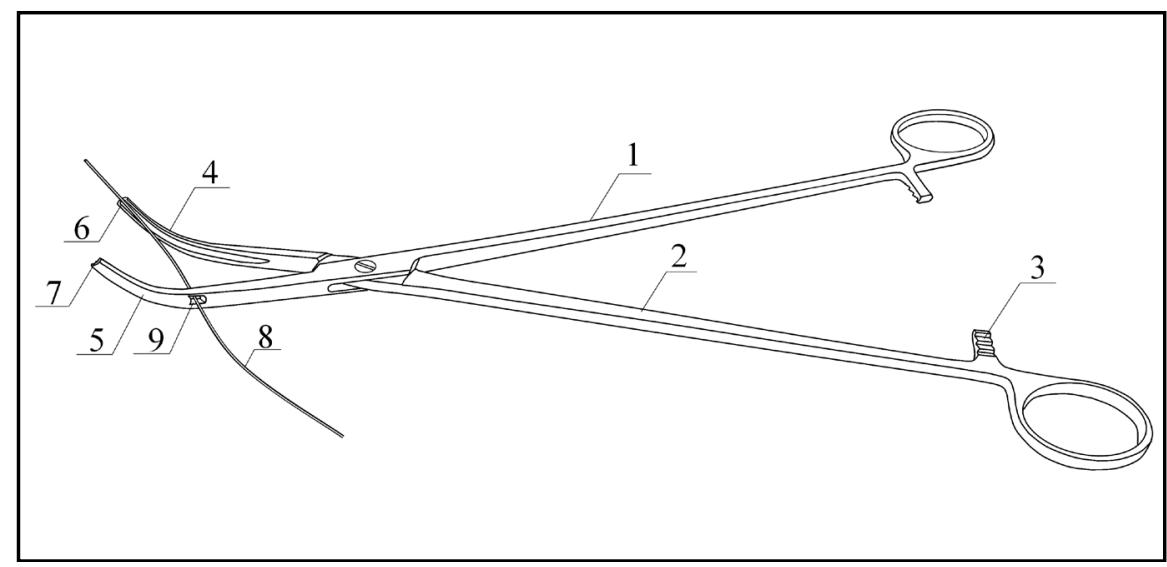

Figure 1. Diagram of utility model \#1 of the author's forceps for performing modified percutaneous dilation tracheostomy.

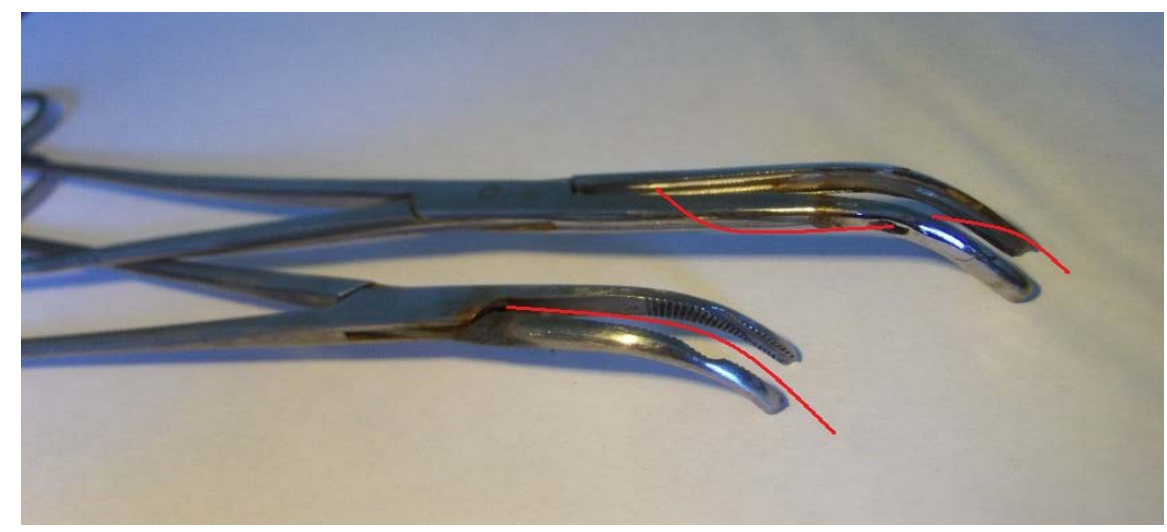

Figure 2. Appearance of utility model \# 1 of the author's forceps in comparison with the Howard-Kelly forceps.

sponges. The grooves are made on $2 / 3$ of the length of the sponges. On the side surfaces, a mesh knurling is applied, and a guidewire 8 is placed in the longitudinal groove 6 of the first working sponge 4 (for the convenience of fixing the string when opening the clamp arms), and a through-side hole 9 is made on the longitudinal groove 7 of the second working sponge 5 for the guidewire.

Tracheostomy using utility model \#1 was performed with the same sequence as when performing any method.

Taking into account that tracheostomy was mainly performed by patients with PALV, the method was performed with bronchoscopic support and monitoring. Therefore, at the first stage of bronchoscopic control, the intubation tube was installed at the appropriate level just above the place of the intended puncture. The second stage was to make a skin incision up to $1.5 \mathrm{~cm}$ long above the jugular notch at the level of the 2nd half-ring of the trachea. The third stage was performed by pushing the superficial fascia of the neck in a blunt way. In this case, you can use one of the medium-sized surgical instruments with narrow branches (such as "mosquito").

The next step was to punctuate the trachea with a thin needle in the area of 2 
semicircles under the control of bronchoscopy and pass a metal guidewire through the needle hole. After removing the needle, a guidewire is passed into the groove and through the hole in the branch of the modified forceps. The next stage is the main stage: dilation of the trachea with a modified instrument. After dilatation of the trachea, a tracheostomy tube of a predetermined size is installed along the conductor without technical difficulties, and then the conductor is removed. The next step is to perform bronchoscopic sanitation and control of the tracheostomy tube, after which the patient is extubated. And the final stage is to connect the patient to a ventilator and fix the tracheostomy tube.

\section{The Results of Applying the Modified Technique of Percutaneous Tracheostomy}

As shown by the analysis of the frequency of complications after MPTS, which is presented in Table 1, the number of complications was noted in 3 patients, and the average number of complications per patient was 1.7. Bleeding occurred in 1 (1.1\%) case, also in one case, there was damage to the tracheal mucosa and emphysema of the neck and face, in $2(2.2 \%)$ cases-infectious complications.

The details of the above-mentioned complications, depending on the presence of one of the risk factors for the development of a complicated course, are presented in Table 2.

Thus, out of 24 patients (with the presence of one or more risk factors), complications were observed in 3 patients, in 1 (4.2\%) case related to technical aspects of tracheostomy and in $2(8.3 \%)$ patients on the background of the General status.

The distribution of patients by the number of risk factors and the frequency of complications after MPTS is shown in Figure 3.

As can be seen from Figure 3, complicated course associated with technical aspects of MPTS was observed only in $1(1.1 \%)$ of 4 patients $(4.3 \%)$ with the

Table 1. The frequency of complications of tracheostomy.

\begin{tabular}{ccc}
\hline & \multicolumn{2}{c}{ MPTS } \\
Complications & total & $\%$ \\
\cline { 2 - 3 } Fleeding & 1 & $1.1 \%$ \\
False move & 0 & $0.0 \%$ \\
Damage to the tracheal mucosa & 1 & $1.1 \%$ \\
Infectious complications & 2 & $2.2 \%$ \\
Emphysema & 1 & $1.1 \%$ \\
Number of complications & & 5 \\
Number of patients with complications & 3 & $3.2 \%$ \\
The average number of complications per patient & & 1.7 \\
\hline
\end{tabular}


Table 2. The frequency of complications after the modified method of percutaneous CU depending on the presence of risk factors.

\begin{tabular}{|c|c|c|c|c|c|c|}
\hline \multirow{3}{*}{ Factors } & \multirow{2}{*}{\multicolumn{2}{|c|}{$\begin{array}{c}\text { Number of } \\
\text { patients }\end{array}$}} & \multicolumn{4}{|c|}{ Complications } \\
\hline & & & \multicolumn{2}{|c|}{$\begin{array}{l}\text { Technical aspects } \\
\text { of tracheostomy }\end{array}$} & \multicolumn{2}{|c|}{$\begin{array}{l}\text { The background } \\
\text { of the General } \\
\text { status of patients }\end{array}$} \\
\hline & total & $\%$ & total & $\%$ & total & $\%$ \\
\hline \multicolumn{7}{|l|}{ Group with risk factor(s) } \\
\hline Obese 3 degrees & 10 & $10.8 \%$ & 0 & $0.0 \%$ & 1 & $10.0 \%$ \\
\hline Short neck & 9 & $9.7 \%$ & 1 & $11.1 \%$ & 0 & $0.0 \%$ \\
\hline History of thyroid surgery & 2 & $2.2 \%$ & 0 & $0.0 \%$ & 0 & $0.0 \%$ \\
\hline $\begin{array}{l}\text { Tracheostomy on the background of } \\
\text { tracheo-broncho-pulmonal complications }\end{array}$ & 19 & $20.4 \%$ & 1 & $5.3 \%$ & 1 & $5.3 \%$ \\
\hline $\begin{array}{l}\text { Tracheostomy on the background of a } \\
\text { long-term ventilator (more than } 7 \text { days) }\end{array}$ & 13 & $14.0 \%$ & 1 & $7.7 \%$ & 1 & $7.7 \%$ \\
\hline Patients with risk factors & 24 & $25.8 \%$ & 1 & $4.2 \%$ & 2 & $8.3 \%$ \\
\hline
\end{tabular}

\section{Group without risk factor(s)}

Without obesity

Normal neck

No operations on the thyroid gland

Without pathology of the trachea, bronchi and lungs

Ventilator up to $3-7$ days

Patients without risk factors

$\begin{array}{llllll}83 & 89.2 \% & 1 & 1.2 \% & 1 & 1.2 \%\end{array}$

${ }^{*}$ Chi-square criteria $=3.384 ; \mathrm{Df}=2 ; \mathrm{p}=0.185$

$\begin{array}{llllll}84 & 90.3 \% & 0 & 0.0 \% & 2 & 2.4 \%\end{array}$

${ }^{*}$ Chi-square criteria $=9.612 ; \mathrm{Df}=2 ; \mathrm{p}=0.009$

$91 \quad 97.8 \% \quad 1 \quad 1.1 \% \quad 2 \quad 2.2 \%$

$\begin{array}{llllll}74 & 79.6 \% & 0 & 0.0 \% & 1 & 1.4 \%\end{array}$

${ }^{\star}$ Chi-square criteria $=5.102 ; \mathrm{Df}=2 ; \mathrm{p}=0.079$

$\begin{array}{llllll}80 & 86.0 \% & 0 & 0.0 \% & 1 & 1.3 \%\end{array}$

${ }^{*}$ Chi-square criteria $=8.543 ; \mathrm{Df}=2 ; \mathrm{p}=0.014$

$\begin{array}{llllll}69 & 74.2 \% & 0 & 0.0 \% & 0 & 0.0 \%\end{array}$

${ }^{*}$ Chi-square criteria $=8.912 ; \mathrm{Df}=2 ; \mathrm{p}=0.012$

Note: ${ }^{*}$ Confidence relative to the indicator with the corresponding risk factor; obesity of the 3rd degree was observed in $10(10.8 \%)$ patients who underwent MPTS, of which in $1(10.0 \%)$ case there was a complicated course on the background of the General status of the patient; short neck was observed in 9 (9.7\%) patients of which $1(11.1 \%)$ had a complication associated with technical aspects of tracheostomy; a history of thyroid surgery occurred in $2(2.2 \%)$ patients who did not affect the development of complications in MPTS; tracheostomy on the background of tracheo-broncho-pulmonal complications was performed in $19(20.4 \%)$ patients of which 2 patients had complications, in $1(5.3 \%)$ case related to technical aspects of tracheostomy and in $1(5.3 \%)$ case-on the background of the General status of the patient; tracheostomy on the background of long-term ventilator (more than 7 days) was performed in $13(14.0 \%)$ patients, 2 of whom had complications, $1(7.7 \%)$ related to technical aspects of tracheostomy and $1(7.7 \%)$ patients on the background of General status. 


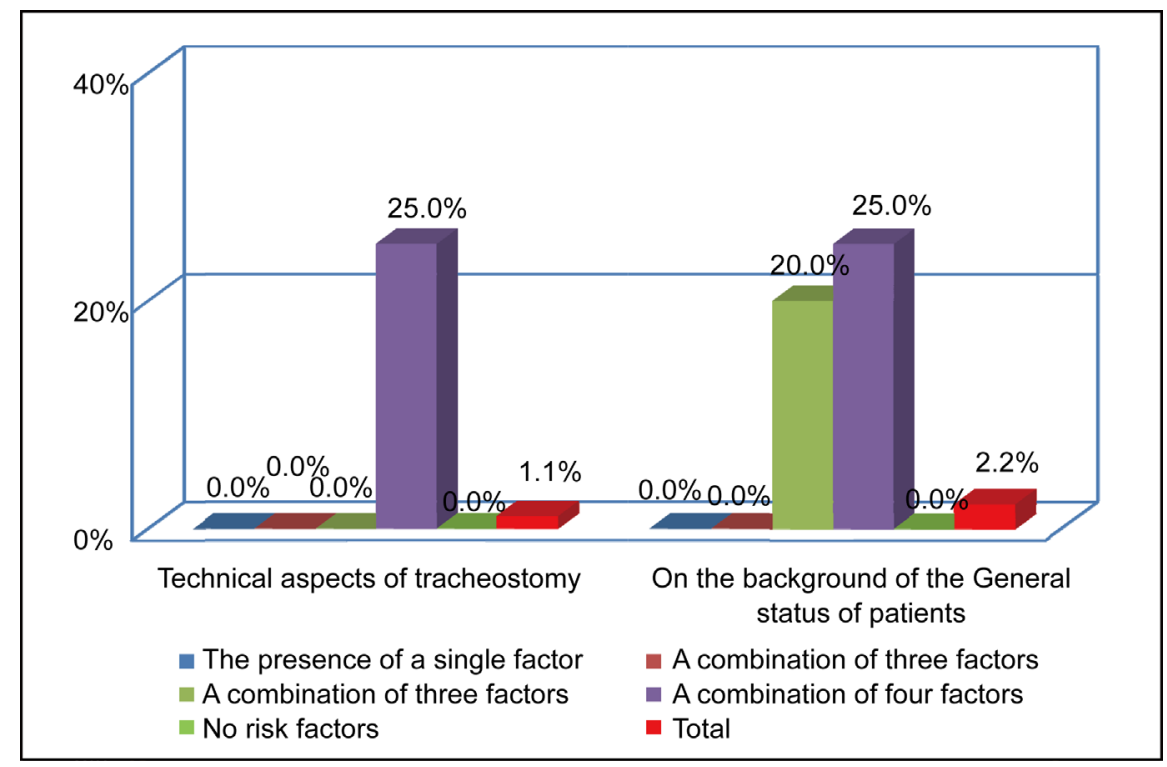

Figure 3. Distribution of patients by the number of risk factors and the frequency of complications after MPTS.

presence of four risk factors. Complicated course after MPTS occurred on the background of the General status of patients was observed only in 2 (2.2\%) with the presence of three and four risk factors, respectively.

As can be seen from Figure 4, complicated course associated with technical aspects of TTS was observed in $5.1 \%$ of patients without risk factors, in $13.6 \%$ of patients with one risk factor, in $20.0 \%$ of patients with two risk factors, in $23.1 \%$ of patients with three risk factors, and in $33.3 \%$ of patients with four risk factors. Complicated course after TTS occurred against the background of the General status of patients was observed in $3.4 \%$ of patients with no risk factors, in $11.4 \%$ of patients with one risk factor, in $17.1 \%$-with two factors, in $38.5 \%$-with three and in $44.4 \%$ - with four risk factors.

The final dependence of the frequency of development of various complications on the presence of risk factors for PTS is most clearly reflected in the diagrams shown in Figure 5. The highest percentage (25.5\%) of complications was observed in patients with the presence of four factors, while complications arising from a short neck were noted in $11.1 \%$ of cases and were mainly associated with technical aspects of tracheostomy. Other risk factors were equally distributed regardless of the cause of the complication. Thus, tracheostomy in the presence of bronchopulmonary complications and tracheostomy in patients with PALV were distributed as risk factors equally regardless of the cause of development: $5.3 \%$ and $7.7 \%$, respectively.

Thus, the improved forceps model for percutaneous dilational tracheostomy improves the technical aspects of manipulation by ensuring stable fixation of the guidewire, thereby reducing the risk of injury to surrounding tissues and the probability of developing specific complications under the influence of various risk factors in only $8.3 \%$ of cases. 


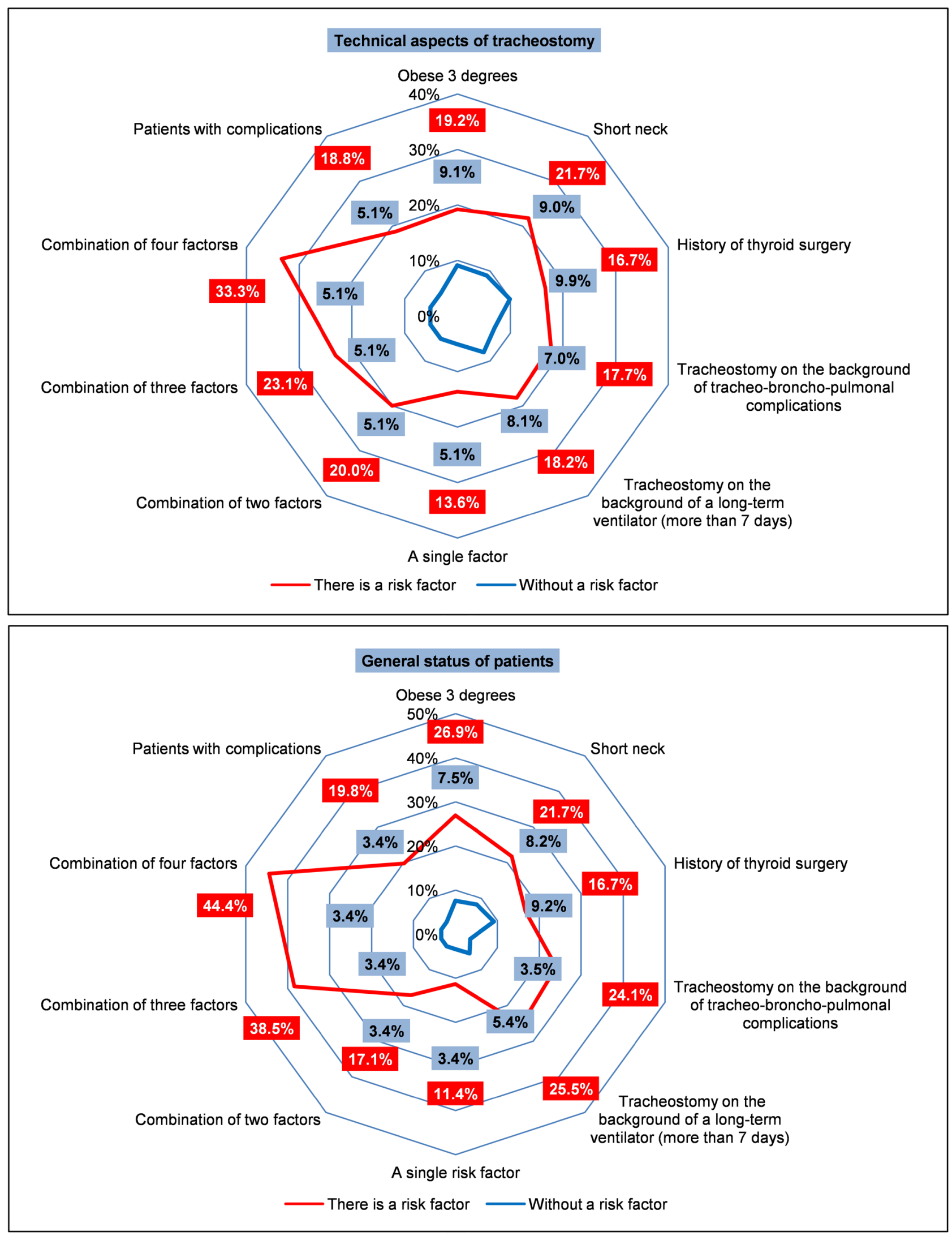

Figure 4. Dependence of the frequency of development of various complications on the presence of risk factors for traditional tracheostomy. 

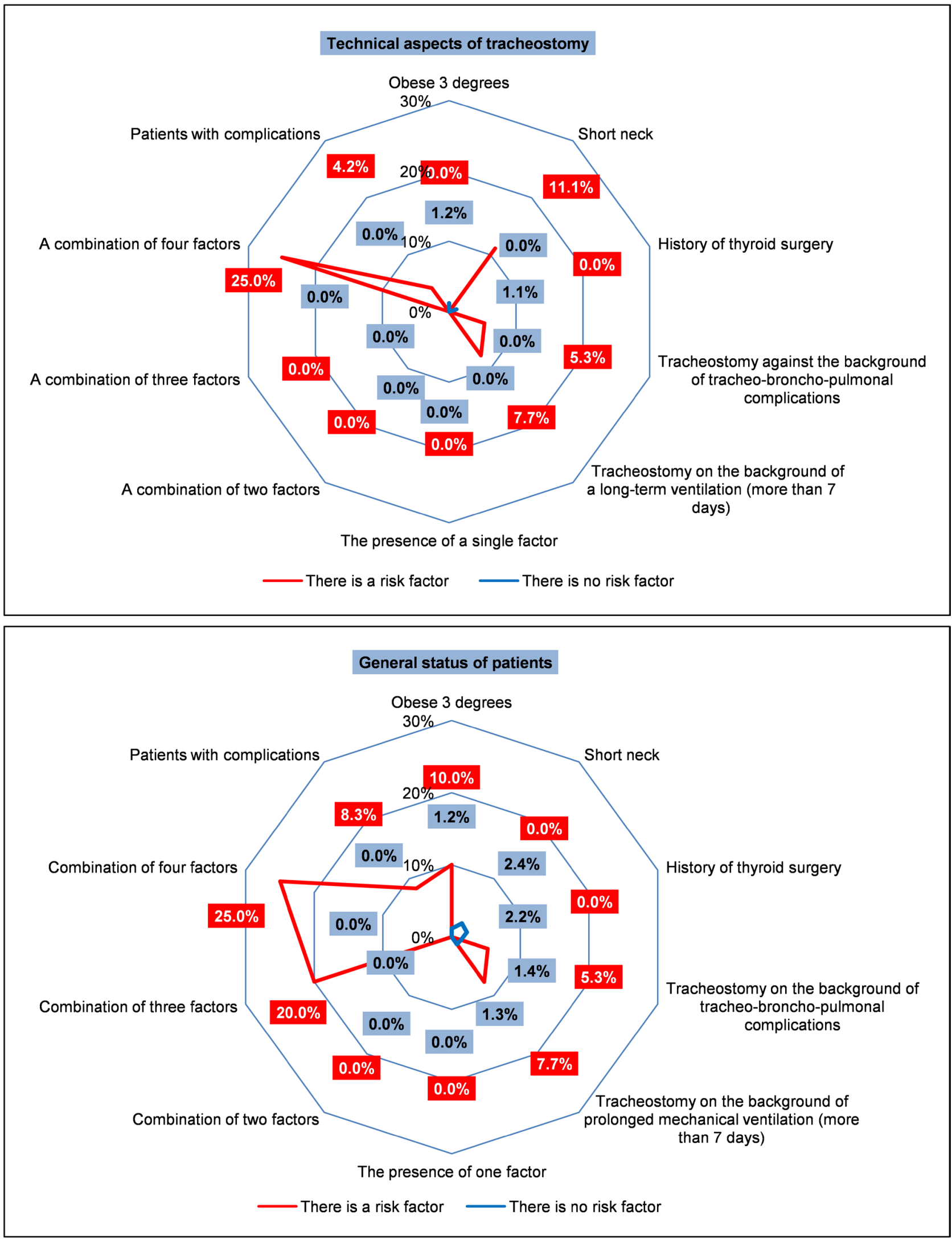

Figure 5. Dependence of the frequency of development of various complications on the presence of risk factors for percutaneous tracheostomy. 


\section{Tracheostomy Results in Comparison Groups}

When comparing the frequency of complications after various methods of TS depending on the presence of risk factors (Table 3 ), it was noted that the total number of patients with complicated course after TTS was 39 (38.6\%), after normal PTS -8 (33.3\%) and after MPTS-3 (12.5\%). Patients with three or four risk factors had the highest percentage of complications. The number of patients

Table 3. Comparative incidence of complications after different TS methods depending on the presence of risk factors.

\begin{tabular}{|c|c|c|c|c|c|c|}
\hline \multirow{3}{*}{ Indicators } & \multicolumn{6}{|c|}{ The frequency of total complications of TS } \\
\hline & \multicolumn{2}{|c|}{ Traditional TS } & \multicolumn{2}{|c|}{ Percutaneous TS } & \multicolumn{2}{|c|}{$\begin{array}{c}\text { Modified } \\
\text { percutaneous TS }\end{array}$} \\
\hline & total & $\%$ & total & $\%$ & total & $\%$ \\
\hline \multicolumn{7}{|l|}{ Group with risk factor(s) } \\
\hline Obese 3 degrees & 12 & $46.2 \%$ & 4 & $44.4 \%$ & 1 & $10.0 \%$ \\
\hline Short neck & 10 & $43.5 \%$ & 4 & $44.4 \%$ & 1 & $11.1 \%$ \\
\hline History of thyroid surgery & 2 & $33.3 \%$ & 1 & $33.3 \%$ & 0 & $0.0 \%$ \\
\hline $\begin{array}{l}\text { Tracheostomy on the background of } \\
\text { tracheo-broncho-pulmonal complications }\end{array}$ & 33 & $41.8 \%$ & 4 & $25.0 \%$ & 2 & $10.5 \%$ \\
\hline $\begin{array}{l}\text { Tracheostomy on the background } \\
\text { of a long-term mechanical ventilation } \\
\text { (more than } 7 \text { days) }\end{array}$ & 24 & $43.6 \%$ & 3 & $30.0 \%$ & 2 & $15.4 \%$ \\
\hline The presence of a single factor & 11 & $25.0 \%$ & 1 & $10.0 \%$ & 0 & $0.0 \%$ \\
\hline A combination of two factors & 13 & $37.1 \%$ & 3 & $37.5 \%$ & 0 & $0.0 \%$ \\
\hline A combination of three factors & 8 & $61.5 \%$ & 2 & $66.7 \%$ & 1 & $20.0 \%$ \\
\hline A combination of four factors & 7 & $77.8 \%$ & 2 & $66.7 \%$ & 2 & $50.0 \%$ \\
\hline $\begin{array}{c}\text { Total patients with complications } \\
\text { due to risk factors }\end{array}$ & 39 & $38.6 \%$ & 8 & $33.3 \%$ & 3 & $12.5 \%$ \\
\hline \multicolumn{7}{|l|}{ Group without risk factor(s) } \\
\hline Without obesity & 42 & $16.7 \%$ & 5 & $8.1 \%$ & 2 & $2.4 \%$ \\
\hline Normal neck & 44 & $17.3 \%$ & 5 & $8.1 \%$ & 2 & $2.4 \%$ \\
\hline No operations on the thyroid gland & 52 & $19.1 \%$ & 8 & $11.8 \%$ & 3 & $3.3 \%$ \\
\hline $\begin{array}{l}\text { Without pathology of the trachea, } \\
\text { bronchi and lungs }\end{array}$ & 21 & $10.6 \%$ & 5 & $9.1 \%$ & 1 & $1.4 \%$ \\
\hline Mechanial ventilation up to 3 - 7 days & 30 & $13.5 \%$ & 6 & $9.8 \%$ & 1 & $1.3 \%$ \\
\hline $\begin{array}{l}\text { Total patients with complications } \\
\text { without risk factors }\end{array}$ & 15 & $8.5 \%$ & 1 & $2.1 \%$ & 0 & $0.0 \%$ \\
\hline
\end{tabular}

Note: Data on the number of patients in the corresponding groups are given in Tables 3-5. 
without risk factors, but with the presence of tracheostomy complications, was distributed as follows: after TTS, complications occurred in 15 (8.5\%) patients, after normal PTS-in $1(2.0 \%)$ and there were practically no complications in patients after MPTS.

A summary analysis of the incidence of complications, regardless of the cause-effect relationship of the latter is presented in Figure 6. As can be seen from the diagram (Figure 6), the highest (96.8\%) percentage of satisfactory results was observed in patients after MPTS, in patients after TTS and PTS, this indicator was $80.6 \%$ and $87.3 \%$, respectively.

Taking into account the fact that the modified method of PTS currently dominates in the RSCS named after acad. Vakhidov. Figure 7 shows a comparative analysis of the frequency of complications after variants of percutaneous TS.

Thus, the complicated course of tracheostomy was observed in $9(12.7 \%) \mathrm{pa}-$ tients after normal PTS and in $3(3.2 \%)$ patients after MPTS. Complications in the presence of risk factors were observed in $8(33.3 \%)$ patients after normal PTS and in $3(12.5 \%)$ patients after MPTS. Complications in the absence of risk factors occurred only in 1 (2.1\%) patient with PTS.

Considering in a comparative aspect the frequency of complications depending on the cause-effect relationship (Table 4, Figure 8), it was noted that the technical aspects of tracheostomy caused complications in $28(10.1 \%)$ patients after TTS, in $6(8.5 \%)$ patients after PTS and in $1(1.1 \%)$ patient after MPTS. Complications that occurred on the background of the General status of patients were observed in 26 (9.4\%) patients after TS, in $3(4.2 \%)$ patients after PTS and 2 (2.2\%) patients after MPTS.

Interesting in our opinion is the distribution of patients with a smooth course of tracheostomy, but having one or more risk factors for complications (Table 5). As can be seen from the table, 55.6\% of patients after PTS with 3rd degree obesity passed without complications, while this indicator in the group of patients with MPTS was $90.0 \%$. The presence of a short neck also did not affect the

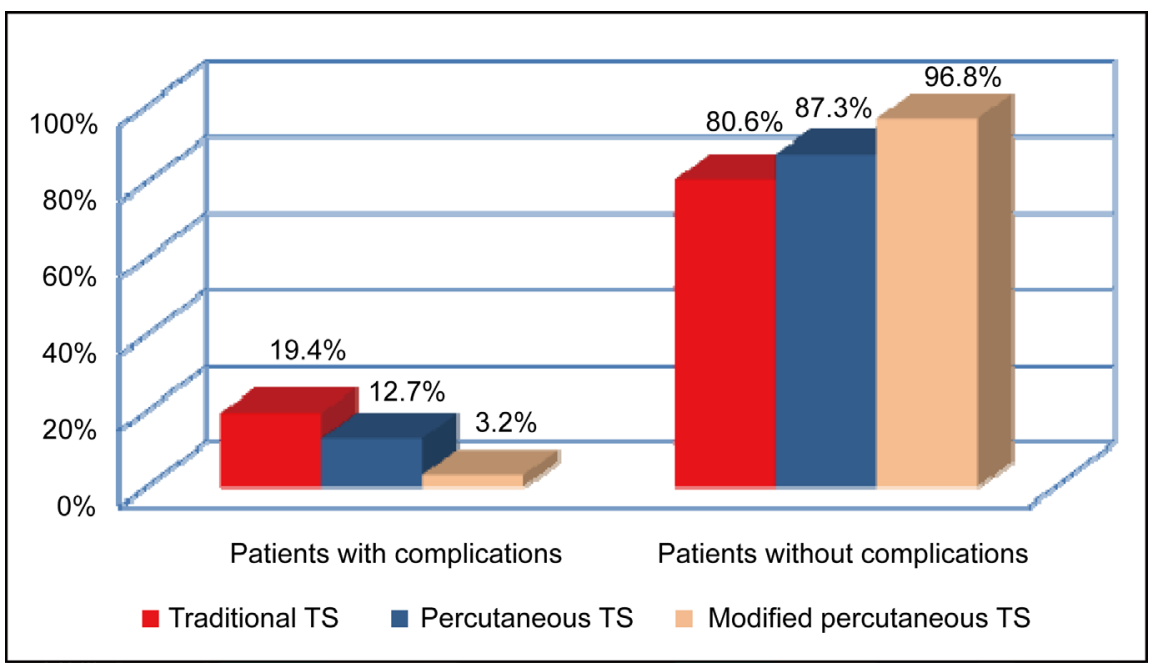

Figure 6. Distribution of patients with complications after tracheostomy. 
Table 4. Frequency of complications related to technical aspects of tracheostomy or the General status of patients.

\begin{tabular}{|c|c|c|c|c|c|c|}
\hline \multirow{2}{*}{ Indicators } & \multicolumn{2}{|c|}{ Traditional TS } & \multicolumn{2}{|c|}{ Percutaneous TS } & \multicolumn{2}{|c|}{$\begin{array}{c}\text { Modified } \\
\text { percutaneous TS }\end{array}$} \\
\hline & total & $\%$ & total & $\%$ & total & $\%$ \\
\hline \multicolumn{7}{|l|}{ Technical aspects of tracheostomy } \\
\hline Bleeding & 16 & $5.8 \%$ & 3 & $4.2 \%$ & 1 & $1.1 \%$ \\
\hline False move & 0 & $0.0 \%$ & 1 & $1.4 \%$ & 0 & $0.0 \%$ \\
\hline Damage to the tracheal mucosa & 25 & $9.0 \%$ & 5 & $7.0 \%$ & 1 & $1.1 \%$ \\
\hline Infectious complications & 12 & $4.3 \%$ & 3 & $4.2 \%$ & 0 & $0.0 \%$ \\
\hline Emphysema & 18 & $6.5 \%$ & 2 & $2.8 \%$ & 1 & $1.1 \%$ \\
\hline Number of patients with complications & 28 & $10.1 \%$ & 6 & $8.5 \%$ & 1 & $1.1 \%$ \\
\hline \multicolumn{7}{|c|}{ Complications after tracheostomy on the background of the General status of patients } \\
\hline $\begin{array}{l}\text { Bleeding on the background of an } \\
\text { infectious process associated with } \\
\text { long-term ventilator, sepsis and MOF }\end{array}$ & 5 & $1.8 \%$ & 0 & $0.0 \%$ & 0 & $0.0 \%$ \\
\hline $\begin{array}{l}\text { Infectious complications on the background } \\
\text { of long-term ventilator, bronchopulmonary } \\
\text { complications, sepsis and MOF }\end{array}$ & 24 & $8.6 \%$ & 3 & $4.2 \%$ & 2 & $2.2 \%$ \\
\hline Number of patients with complications & 26 & $9.4 \%$ & 3 & $4.2 \%$ & 2 & $2.2 \%$ \\
\hline
\end{tabular}

Table 5. Number of patients without complications after percutaneous TS depending on the presence of risk factors.

\begin{tabular}{|c|c|c|c|c|}
\hline \multirow{2}{*}{ Indicator } & \multicolumn{2}{|c|}{ Percutaneous TS } & \multicolumn{2}{|c|}{ Modified percutaneous TS } \\
\hline & total & $\%$ & total & $\%$ \\
\hline \multicolumn{5}{|l|}{ Group with risk factor(s) } \\
\hline Obese 3 degrees & 5 & $55.6 \%$ & 9 & $90.0 \%$ \\
\hline Short neck & 5 & $55.6 \%$ & 8 & $88.9 \%$ \\
\hline History of thyroid surgery & 2 & $66.7 \%$ & 2 & $100.0 \%$ \\
\hline $\begin{array}{l}\text { Tracheostomy on the background of } \\
\text { tracheo-broncho-pulmonal complications }\end{array}$ & 12 & $75.0 \%$ & 17 & $89.5 \%$ \\
\hline $\begin{array}{l}\text { Tracheostomy on the background of a } \\
\text { long-term ventilator (more than } 7 \text { days) }\end{array}$ & 7 & $70.0 \%$ & 11 & $84.6 \%$ \\
\hline Patients with risk factors & 16 & $66.7 \%$ & 21 & $87.5 \%$ \\
\hline \multicolumn{5}{|l|}{ Group without risk factor(s) } \\
\hline Without obesity & 57 & $91.9 \%$ & 81 & $97.6 \%$ \\
\hline Normal neck & 57 & $91.9 \%$ & 82 & $97.6 \%$ \\
\hline No operations on the thyroid gland & 60 & $88.2 \%$ & 88 & $96.7 \%$ \\
\hline $\begin{array}{l}\text { Without pathology of the trachea, } \\
\text { bronchi and lungs }\end{array}$ & 50 & $90.9 \%$ & 73 & $98.6 \%$ \\
\hline Ventilator up to $3-7$ days & 55 & $90.2 \%$ & 79 & $98.8 \%$ \\
\hline Patients without risk factors & 46 & $97.9 \%$ & 69 & $100.0 \%$ \\
\hline
\end{tabular}




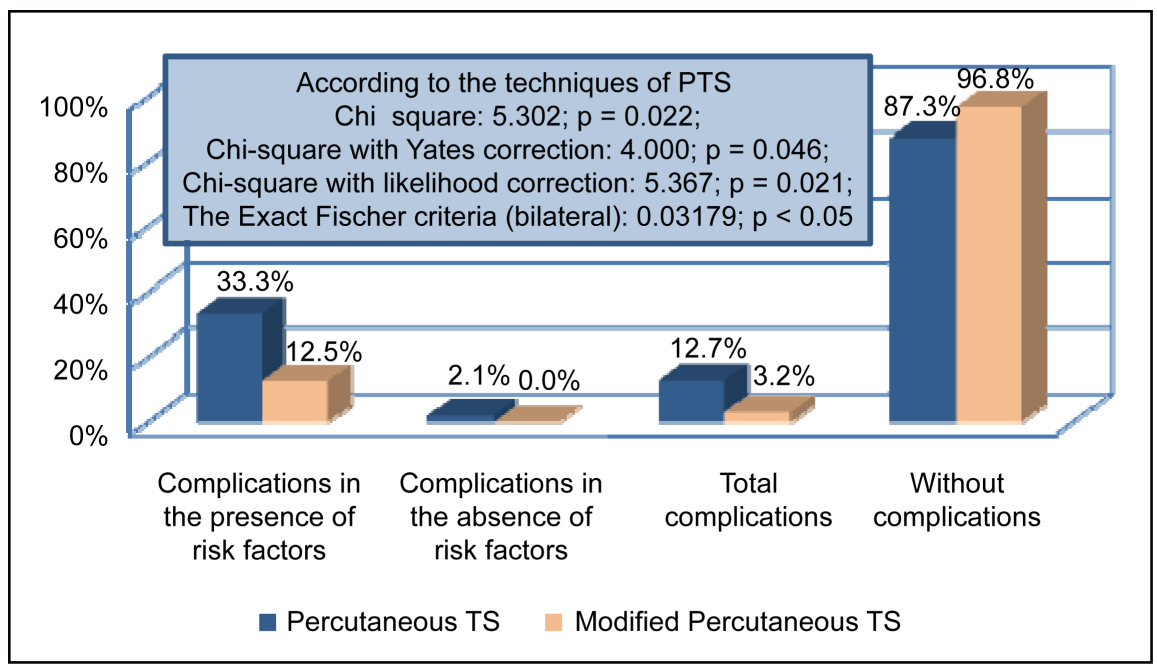

Figure 7. Comparative incidence of complications after percutaneous TS.

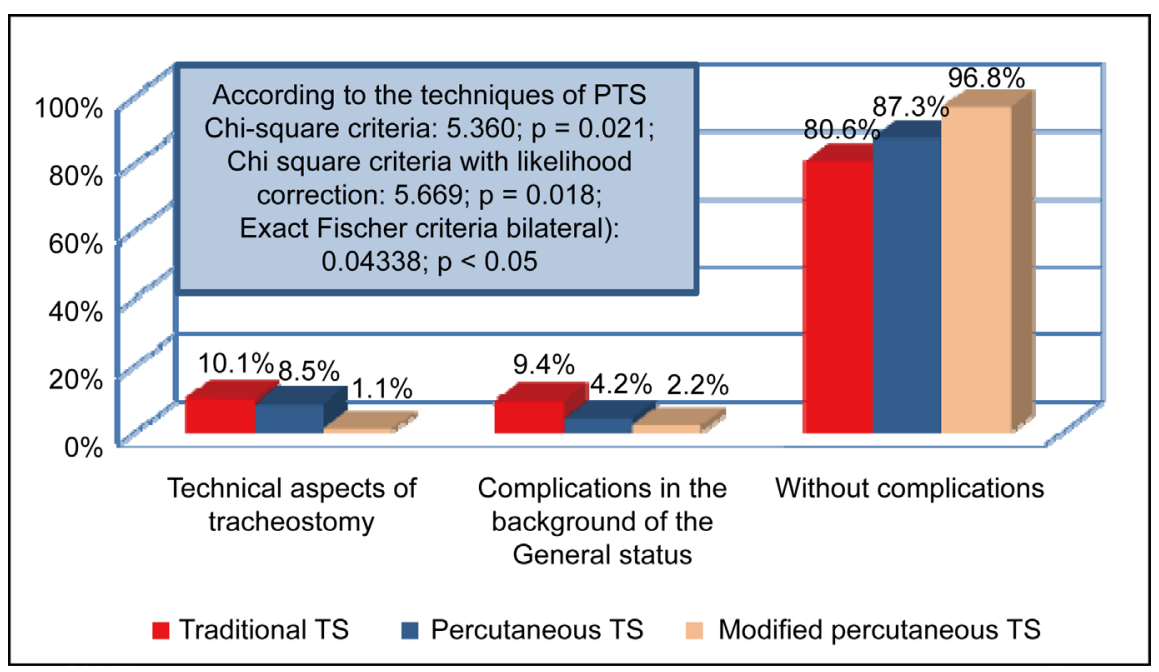

Figure 8. Comparative incidence of complications related to the technical aspects of tracheostomy and the general status of patients.

development of complications in $55.6 \%$ of patients after PTS and $88.9 \%$ after MPTS. Thyroid surgery in the anamnesis did not affect the development of complications in $66.7 \%$ of patients with PTS and in $100 \%$ of patients with MPTS. Tracheostomy on the background of broncho-pulmonary complications and prolonged artificial lung ventilation was successful in $75.0 \%$ and $70.0 \%$, respectively, after PTS, and in $89.5 \%$ and $84.6 \%$ of patients, respectively, after MPTS.

Thus, uncomplicated course after tracheostomy in patients with risk factors was observed in $16(66.7 \%)$ patients after PTS and 21 (87.5\%) patients after MPTS.

Figure 9 shows the distribution by the number of risk factors and the frequency of complications in different types of PTS.

Thus, in MPTS, complications occurred only in patients with three (20\%) or four (50\%) risk factors, whereas in PTS, complications are observed in almost all 
cases, and even in patients without risk factors (2.1\%).

The indicator of tracheostomy completion time may be of particular interest for practical surgeons. Of course, this indicator is conditional and depends on many reasons. However, the average time calculated on such a large clinical material will reflect the real indicator (Figure 10).

For example, the average TTS execution time was $24.1 \pm 0.6$ minutes, for normal PTS $-8.4 \pm 0.3$ minutes, and for MPTS $-7.6 \pm 0.2$ minutes.

In the long-term period, 173 (62.2\%) patients were followed up after TTS, 56 (80.6\%) after PTS, and 75 (80.6\%) patients after MPTS. As is known, the main complication of the long-term period after tracheostomy is the formation of tracheal stenosis.

Figure 11 shows the frequency of tracheal stenosis formation in comparison groups. Thus, the highest percentage of stenosis was observed in patients after TTS and amounted to $12.1 \%$ (21), after PTS this indicator was noted in $8.9 \%$ (5) of cases and after MPTS in just 1.3\% (1).

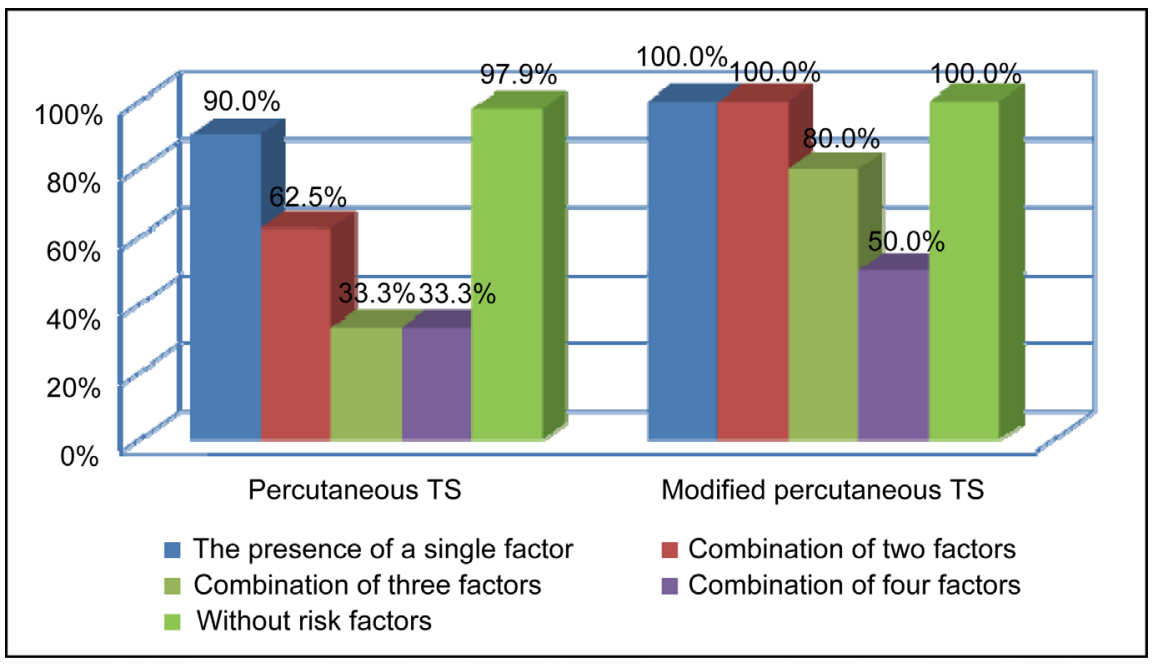

Figure 9. Distribution of patients by the number of risk factors and favorable outcomes after variants of PTS.

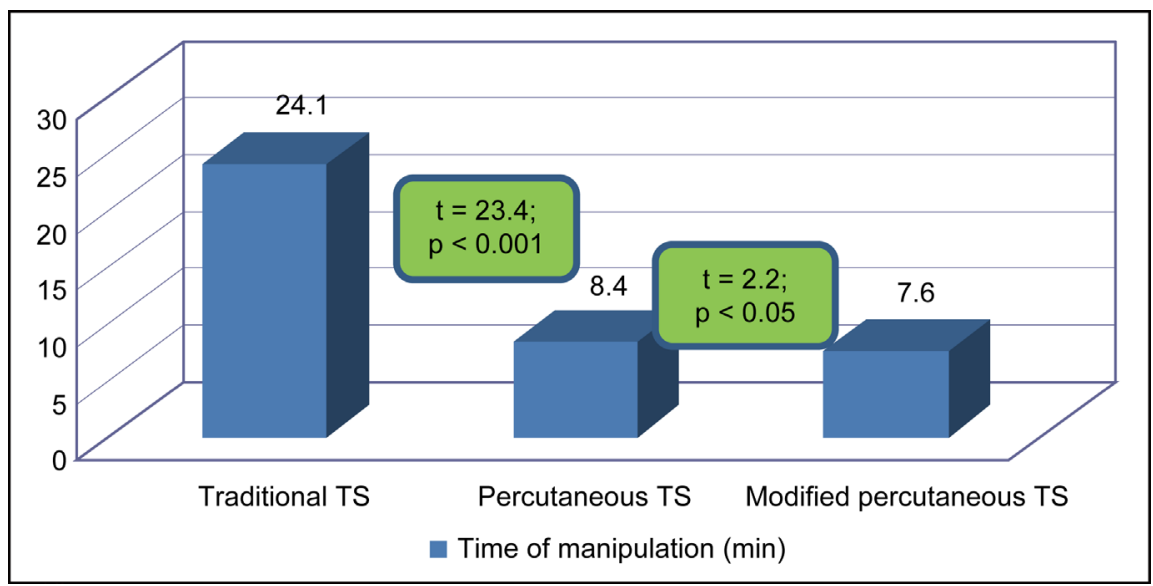

Figure 10. The average time to perform a tracheostomy. 


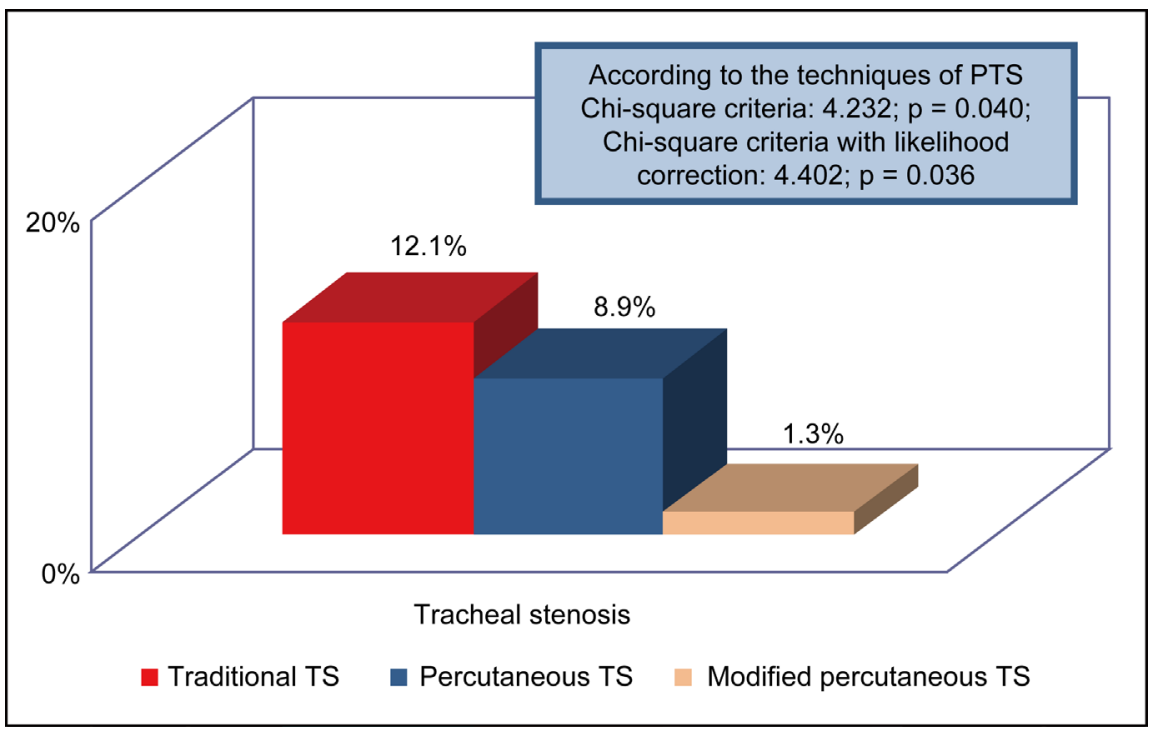

Figure 11. Frequency of tracheal stenosis formation in comparison groups.

Thus, in a comparative perspective the proposed technique percutaneous tracheostomy has reduced the incidence of complications in the presence of risk factors from $33.3 \%$ (8 out of 24 patients with the standard technique) to $12.5 \%$ ( 3 of 24 patients) in the absence of factors from $2.1 \%$ ( 1 of 47 patients) to 0 , and in General from 12.7\% (9 out of 71 patients) to $3.2 \%$ ( 3 of 93 patients) (Chi-square $=5.302 ; \mathrm{p}=0.022$ ), and the frequency of formation of tracheal stenosis from $8.9 \%$ ( 5 out of 56 patients), 1.3\% ( 1 of 75 patients) (Chi-square $=$ $4.232 ; \mathrm{p}=0.040)$.

\section{Conclusions}

The analysis made it possible to draw the following conclusion:

The improved forceps model for percutaneous dilational tracheostomy improves the technical aspects of manipulation by ensuring stable fixation of the guidewire, thereby reducing the risk of injury to surrounding tissues and the likelihood of developing specific complications under the influence of various risk factors in only $8.3 \%$ of cases.

In a comparative perspective the proposed technique percutaneous tracheostomy has reduced the incidence of complications in the presence of risk factors from $33.3 \%$ ( 8 out of 24 patients with the standard technique) to $12.5 \%$ ( 3 of 24 patients) in the absence of factors from $2.1 \%$ ( 1 of 47 patients) to 0 , and in general from $12.7 \%$ (9 out of 71 patients) to $3.2 \%$ ( 3 of 93 patients) (Chi-square $=$ 5.302; $\mathrm{p}=0.022)$ and the frequency of formation of tracheal stenosis from $8.9 \%$ ( 5 out of 56 patients), 1.3\% ( 1 of 75 patients) (Chi-square $=4.232 ; \mathrm{p}=0.040$ ).

\section{Conflicts of Interest}

The authors declare no conflicts of interest regarding the publication of this paper. 


\section{References}

[1] Scales, D.C. and Cuthbertson, B.H. (2014) Percutaneous Dilatational Tracheostomy: Mostly Safe, But Do Benefits Outweigh Risks? Critical Care, 18, Article No. 117. https://doi.org/10.1186/cc13761

[2] Simon, M., Metschke, M., Braune, S.A., Püschel, K. and Kluge, S. (2013) Death after Percutaneous Dilatational Tracheostomy: A Systematic Review and Analysis of Risk Factors. Critical Care, 17, Article No. R258. https://doi.org/10.1186/cc13085

[3] Durbin, C.G. (2010) Tracheostomy: Why, When, and How? Respiratory Care, 55, 1056-1068.

[4] Khudaybergenov, S., Eshonkhodjaev, O., Abdusalomov, S. and Amanov, B. (2017) Extended Resection of the Trachea in a Patient with Cicatricial Tracheal Stenosis after Tracheostomy Complicated with Esophageal-Tracheal Fistula and Extensive Defect of the Frontal Tracheal Wall. Kardiochirurgia $i$ Torakochirurgia Polska, 14, 55-58. https://doi.org/10.5114/kitp.2017.66933

[5] Sollid, S.J. and Soreide, E. (2014) Human Factors Play a Vital Role in the Outcome of Percutaneous Dilatational Tracheostomy. Critical Care, 18, Article No. 409. https://doi.org/10.1186/cc13739

[6] Yaghoobi, S., Kayalha, H., Ghafouri, R., Yazdi, Z. and Khezri, M.B. (2014) Comparison of Complications in Percutaneous Dilatational Tracheostomy versus Surgical Tracheostomy. Global Journal of Health Science, 6, Article ID: 33563.

https://doi.org/10.5539/gjhs.v6n4p221 